\title{
Long-acting bronchodilators with or without inhaled corticosteroids and 30-day readmission in patients hospitalized for COPD
}

This article was published in the following Dove Press journal:

International Journal of COPD

3I January 2017

Number of times this article has been viewed

\author{
Raju Bishwakarma' \\ Wei Zhang' \\ Yong-Fang Kuo ${ }^{2,3}$ \\ Gulshan Sharma ${ }^{1,3}$ \\ 'Department of Internal Medicine, \\ Division of Pulmonary, Critical \\ Care and Sleep Medicine, ${ }^{2}$ Office of \\ Biostatistics, ${ }^{3}$ Sealy Center of Aging, \\ University of Texas Medical Branch, \\ Galveston, TX, USA
}

Background: The ability of a long-acting muscarinic antagonist (LAMA) and long-acting beta 2 agonists (LABAs; long-acting bronchodilators, LABDs) with or without inhaled corticosteroids (ICSs) to reduce early readmission in hospitalized patients with COPD is unknown.

Methods: We studied a 5\% sample of Medicare beneficiaries enrolled in Medicare parts A, B and D and hospitalized for COPD in 2011. We examined prescriptions filled for LABDs with or without ICSs (LABDs \pm ICSs) within 90 days prior to and 30 days after hospitalization. Primary outcome was the 30-day readmission rate between "users" and "nonusers" of LABDs \pm ICSs. Propensity score matching and sensitivity analysis were performed by limiting analysis to patients hospitalized for acute exacerbation of COPD (AECOPD). Among 6,066 patients hospitalized for COPD, 3,747 (61.8\%) used LABDs \pm ICSs during the specified period. The "user" and "nonuser" groups had similar rates of all-cause emergency room (ER) visits and readmissions within 30 days of discharge date $(22.4 \%$ vs $20.7 \%, P$-value $0.11 ; 18.0 \%$ vs $17.8 \%$, $P$-value 0.85 , respectively). However, the "users" had higher rates of COPD-related ER visits (5.3\% vs 3.4\%, $P$-value 0.0006 ), higher adjusted odds ratio (aOR) 1.47 (95\% CI, 1.11-1.93) and readmission $(7.8 \%$ vs $5.0 \%, P$-value $<0.0001$ and aOR 1.48 [95\% CI, 1.18-1.86]) than "nonusers". After propensity score matching, the aOR of COPD-related ER visits was 1.45 (95\% CI, 1.07-1.96) and that of readmission was 1.34 (95\% CI, 1.04-1.73). The results were similar when restricted to patients hospitalized for AECOPD.

Conclusion: Use of LABDs \pm ICSs did not reduce 30-day readmissions in patients hospitalized for COPD.

Keywords: COPD, readmission, long-acting bronchodilators, Medicare

\section{Introduction}

The natural history of COPD includes progressive expiratory air flow limitation interrupted by exacerbations. ${ }^{1-4}$ Most exacerbations can be managed in outpatient settings. ${ }^{3}$ However, severe exacerbations require acute care hospitalizations. ${ }^{3}$ Exacerbations are associated with a decline in lung function, ${ }^{4-7}$ reduced quality of life, ${ }^{5,7,8}$ increased mortality, ${ }^{9,10}$ increased risk of further exacerbations ${ }^{7,11,12}$ and increased financial burden to the health-care system. ${ }^{13,14}$ Reducing exacerbations - particularly severe exacerbations - requiring hospitalization is the goal for improving patient care and reducing health-care expenditures.

In the US, of patients aged 65 years and older hospitalized for COPD, one in five were readmitted within 30 days, ${ }^{15-17}$ but less than half of those readmissions were COPD-related. ${ }^{17}$ Due to the high cost to Medicare of readmission, in 2014, the Center for Medicare and Medicaid Services (CMS) added readmission for COPD as
Correspondence: Raju Bishwakarma Division of Pulmonary, Critical Care and Sleep Medicine, University of Texas Medical Branch, 30I University Boulevard, 5.140 John Sealy Annex, Galveston, TX 77555-056I, USA

Tel +l 4097722436

Fax + I 4097729532

Email rajucentury@gmail.com 
a condition for which it would penalize hospitals with higher than expected rates. ${ }^{15}$

COPD readmission represents a complex interplay of patient, provider and system factors. Interventions such as self-management, education, medication reconciliation, early follow-up, patient navigator, transition coach and home visits have been shown to reduce early readmission, ${ }^{18-21}$ but none of these interventions target patients with COPD. A recent systematic review of five randomized controlled trials specially targeting the COPD population failed to show any intervention that impacted readmission. ${ }^{22}$ A single-center randomized controlled trial targeting smoking cessation, inhaler education, screening for gastroesophageal reflux disease and anxiety, and a postdischarge follow-up call failed to show a reduction in readmission. ${ }^{23}$

The Global initiative for chronic Obstructive Lung Disease (GOLD) guidelines recommend the use of longacting bronchodilators (LABDs), such as long-acting muscarinic antagonist (LAMA) and long-acting beta 2 agonists (LABAs) with or without inhaled corticosteroids (ICSs) in patients with moderate to severe disease and those with frequent exacerbations. ${ }^{3}$ Use of these medications has been shown to increase the number of symptom-free days, improve quality of life, decrease moderate to severe exacerbations, decrease hospitalizations and slow the decline in lung function..$^{3,24-26}$ Roflumilast, a phosphodiesterase-4 inhibitor, was shown to reduce moderate to severe exacerbations and also all-cause readmissions within 30 days in a select group of patients with COPD. ${ }^{27,28}$

The purpose of this study is to examine the rate of 30-day readmission in patients who received LABDs with or without LABDs \pm ICSs within 90 days prior to and 30 days after the index hospitalization for COPD. Our hypothesis is that use of maintenance drugs is associated with a reduction in the 30-day readmission rate.

\section{Methods}

\section{Data source}

This study uses files from the 5\% national Medicare sample in 2011 provided by the Research Data Assistance Center (ResDAC). Data from the following files were used: 1) Denominator File (Medicare enrollment information and demographic data); 2) Medicare Provider Analysis and Review file (claims for hospital inpatient and skilled nursing facility stays); 3) Outpatient Standard Analytic File (hospital outpatient services); 4) 100\% Physician/Supplier File (physician and other medical services); 5) Part D drug event data; and 6) Durable Medical Equipment (DME) File. ResDAC provides deidentified data for research purposes, and, due to the nature of the study, the University of Texas Medical Branch IRB deemed that patient consent was not required for this study. The study was approved by the University of Texas Medical Branch Institutional Review Board (IRB Project 09-054).

\section{Study cohort}

Establishment of the study cohort is shown in Figure 1. In 2011, 6,066 patients aged 66 years or older with COPD had an index hospitalization, were discharged home alive, enrolled in Medicare parts A, B and D, but not in a health maintenance organization (HMO), from 1 year prior to 3 months after the index hospitalization, and resided in one of nine US geographic regions. Patients were enrolled from January 1, 2011, to December 31, 2011, and we looked back 1 year prior to index hospitalization (up to January 1, 2010) for baseline characteristics and 30 days after discharge (up to January 31 , 2012) for readmission. COPD hospitalization was defined as, 1) hospitalization with a primary International Classification of Diseases, Ninth Revision (ICD-9) code for COPD (491.21, 491.22, 491.8, 491.9, 492.8, 493.20, 493.21, 493.22 and 496), or 2) primary ICD-9 codes for respiratory failure (518.81, 518.82, 518.84 and 799.1) and secondary ICD-9 codes for COPD, as described earlier. All other hospitalizations were classified as non-COPD related. An "index hospitalization" was defined as the first COPD hospitalization of the year.

\section{Variables}

Subject demographic characteristics were obtained from the Denominator File and included the following: age (66-74 years, $75-84$ years and $\geq 85$ years), gender (male and female), race (non-Hispanic white, black and others), region (New England, Middle Atlantic, East North Central, West North Central, South Atlantic, East South Central, West South Central, Mountain and Pacific) and socioeconomic status. Low socioeconomic status was based on the eligibility for at least 1 month during the index year for state buy-in coverage provided by the Medicaid program. The index hospitalization characteristics included admission type and number of Elixhauser comorbidities $(0,1$, 2 and $>2$ ). Hospital characteristics included number of hospital beds and medical school affiliation. The following parameters were included as surrogates for severity of baseline disease: number of any hospitalizations, oxygen therapy and pulmonary specialist visits in the year before the index hospitalization; intensive care unit (ICU) or coronary care unit (CCU) use; mechanical ventilation; length of hospital stay and pulmonary specialist visit during index hospitalization. 


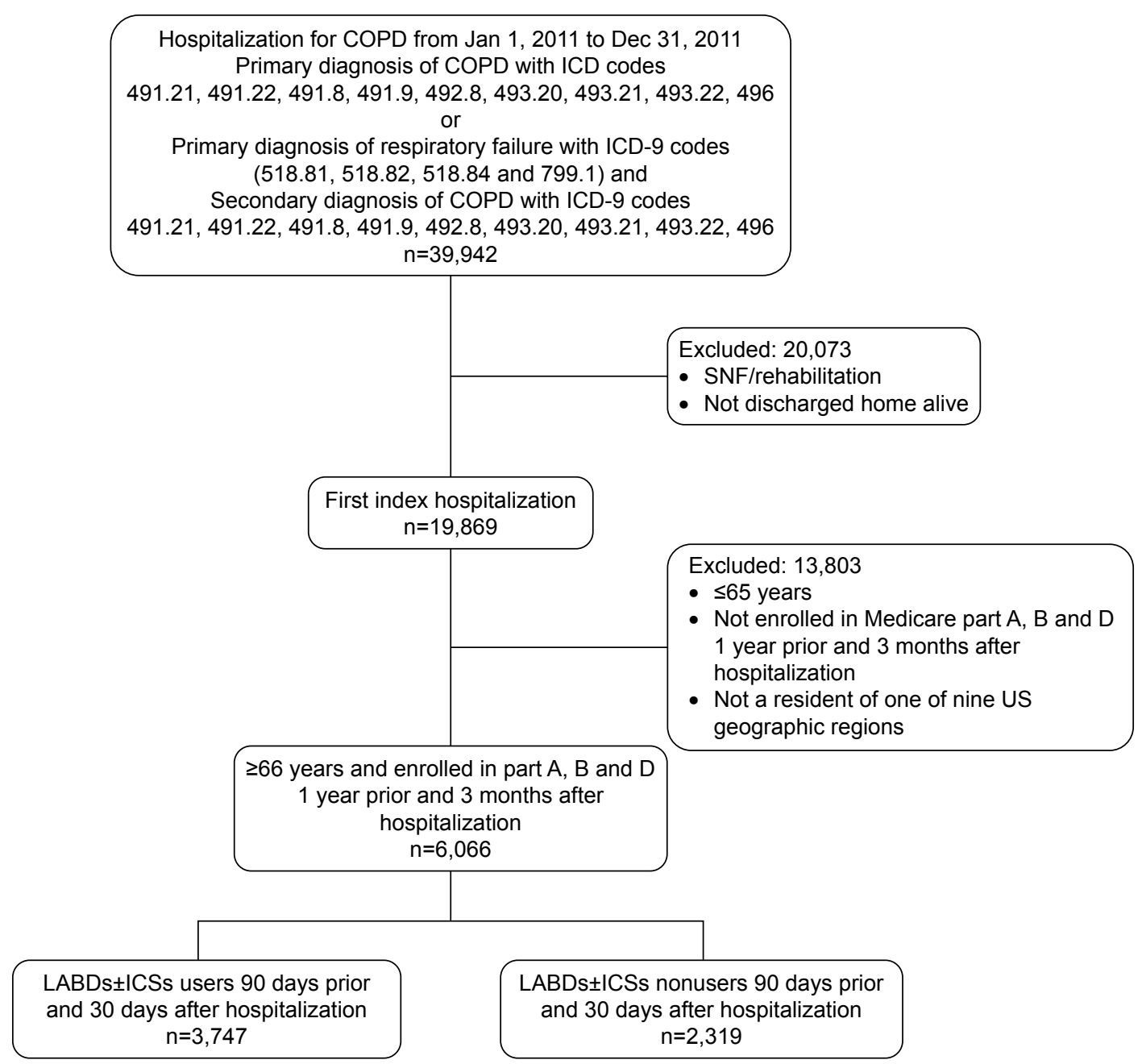

Figure I Establishment of study cohort.

Abbreviations: ICD, International Classification of Diseases; ICD-9, ICD, Ninth Revision; LABDs, long-acting bronchodilators; ICSs, inhaled corticosteroids; Jan, January; Dec, December; SNF, skilled nursing facility.

\section{Exposure}

We defined the "user" group as those who filled a prescription of LABDs \pm ICSs, such as LAMA and LABAs with or without ICSs, from 90 days prior to the index hospitalization to 30 days after the discharge date (Figure 2). We chose the time period of 90 days prior to index hospitalization and 30 days after discharge to classify exposure appropriately. Most prescriptions (73.8\%) were filled as a 30-day supply; however, a mail-in order can be for a 90-day supply. In order to capture the latter, we extended the look back period to 90 days prior to hospitalization. Those with no prescription filled for these medications within this period were included in the "nonuser" group.

Among "users", we also calculated medication adherence as the proportion of days covered (PDC), defined as the proportion of days out of 120 days that a patient had maintenance medication available. For overlap prescription of maintenance medication, an average PDC was calculated.

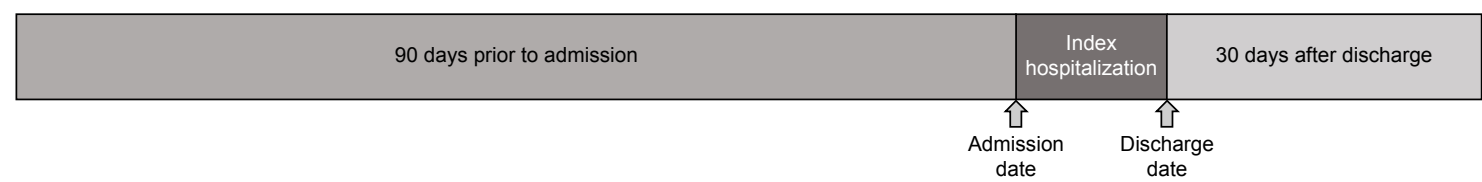

Figure 2 Prescription for long-acting bronchodilators, with or without ICSs, filled by patients with COPD 90 days prior to index hospitalization to 30 days after the discharge in 20II.

Abbreviation: ICSs, inhaled corticosteroids. 


\section{Outcomes}

Our primary outcome of interest was health-care utilization, defined as emergency room (ER) visit and readmission within 30 days after discharge from the acute care hospital. We calculated the unadjusted cost associated with a 30-day readmission stay after index discharge in "users" and "nonusers" based on CMS methodology.

\section{Statistical analysis}

Characteristics were expressed as mean \pm standard deviation for continuous variables and as percentages for categorical variables. Categorical variables were compared using the chi square test. Logistic regression model was used to estimate odds ratios, adjusted for the variables in Table 1 .

Table I Baseline characteristics of LABDs with or without ICSs user and nonuser patients hospitalized with COPD in 2011

\begin{tabular}{|c|c|c|c|}
\hline \multirow{2}{*}{$\begin{array}{l}\text { Demographic } \\
\text { characteristics }\end{array}$} & \multicolumn{2}{|l|}{ LABDs \pm ICSs } & \multirow[t]{2}{*}{ P-value } \\
\hline & Users $^{a}$ & Nonusers $^{b}$ & \\
\hline Total & 3,747 (6I.77) & $2,319(38.23)$ & \\
\hline Age (mean $\pm S D)$ & $76.50 \pm 7.04$ & $77.50 \pm 7.49$ & $<0.0001$ \\
\hline Age group, years & & & $<0.0001$ \\
\hline $66-74$ & $\mathrm{I}, 676(44.73)$ & 941 (40.58) & \\
\hline $75-84$ & $\mathrm{I}, 5 \mathrm{I} 0(40.30)$ & 922 (39.76) & \\
\hline$\geq 85$ & $561(14.97)$ & $456(19.66)$ & \\
\hline Gender & & & 0.32 \\
\hline Female & $2,539(67.76)$ & I,543 (66.54) & \\
\hline Male & $1,208(32.24)$ & $776(33.46)$ & \\
\hline Race & & & 0.02 \\
\hline White & 3,147 (83.99) & $1,974(85.12)$ & \\
\hline Black & $375(10.01)$ & $244(10.52)$ & \\
\hline Others & $225(6.00)$ & 101 (4.36) & \\
\hline Low socioeconomic status & & & $<0.0001$ \\
\hline No & $2,07 \mid(55.27)$ & $\mathrm{I}, 4 \mathrm{I} 4(60.97)$ & \\
\hline Yes & $\mathrm{I}, 676(44.73)$ & $905(39.03)$ & \\
\hline Region & & & $<0.0001$ \\
\hline New England & $222(5.92)$ & $123(5.30)$ & \\
\hline Middle Atlantic & $514(13.72)$ & $261(11.25)$ & \\
\hline East North Central & $719(19.19)$ & $446(19.23)$ & \\
\hline West North Central & $223(5.95)$ & $120(5.17)$ & \\
\hline South Atlantic & $814(21.72)$ & $548(23.63)$ & \\
\hline East South Central & $370(9.87)$ & $295(12.72)$ & \\
\hline West South Central & 408 (10.89) & $295(12.72)$ & \\
\hline Mountain & $123(3.28)$ & $71(3.06)$ & \\
\hline Pacific & $354(9.45)$ & $160(6.90)$ & \\
\hline Number of hospital beds & & & 0.05 \\
\hline$<250$ & $\mathrm{I}, 652$ (44.09) & I,09I (47.05) & \\
\hline $250-499$ & $\mathrm{I}, 327(35.4 \mathrm{I})$ & 797 (34.37) & \\
\hline$\geq 500$ & $768(20.50)$ & 431 (18.59) & \\
\hline Medical school affiliation & & & 0.06 \\
\hline Major & 659 (17.59) & $356(15.35)$ & \\
\hline Minor & $850(22.68)$ & $525(22.64)$ & \\
\hline None & $2,238(59.73)$ & $\mathrm{I}, 438(62.0 \mathrm{I})$ & \\
\hline Type of hospital & & & 0.0002 \\
\hline Government & $460(12.28)$ & $359(15.48)$ & \\
\hline For-profit & $2,637(70.38)$ & I,524 (65.72) & \\
\hline Nonprofit & $650(17.35)$ & $436(18.80)$ & \\
\hline
\end{tabular}

(Continued)
Table I (Continued)

\begin{tabular}{llll}
\hline $\begin{array}{l}\text { Demographic } \\
\text { characteristics }\end{array}$ & \multicolumn{2}{l}{ LABDs \pm ICSs } & P-value \\
\cline { 2 - 3 } & Users $^{\mathbf{a}}$ & Nonusers $^{\mathbf{b}}$ & \\
\hline Admission type & & 0.04 \\
$\quad$ Emergency & $2,825(75.39)$ & $1,683(72.57)$ & \\
$\quad$ Urgent & $624(16.65)$ & $443(19.10)$ & \\
$\quad$ Others & $298(7.95)$ & $193(8.32)$ & \\
Number of comorbidities & & & 0.08 \\
0 & $373(9.95)$ & $233(10.05)$ & \\
I & $574(15.32)$ & $340(14.66)$ & \\
2 & $667(17.80)$ & $360(15.52)$ & \\
$\geq 3$ & $2,133(56.93)$ & $1,386(59.77)$ &
\end{tabular}

Number of hospitalizations in the I year before index

0.37

hospitalization

$\begin{array}{lll}0 & 1,789(47.74) & 1,147(49.46) \\ \mathrm{I} & 936(24.98) & 548(23.63) \\ \geq 2 & \mathrm{I}, 022(27.28) & 624(26.91)\end{array}$

ICU/CCU stay during hospitalization

$\begin{array}{lll}\text { No } & 2,521(67.28) & 1,620(69.86) \\ \text { Yes } & 1,226(32.72) & 699(30.14)\end{array}$

Mechanical ventilation during hospitalization

No $\quad 3,658(97.62) \quad 2,273(98.02)$

Yes $\quad 89(2.38) \quad 46$ (1.98)

Oxygen therapy use I year before index hospitalization

No $\quad$ I,907 (50.89) I,476 (63.65)

Yes $\quad$ I,840 (49.II) $843(36.35)$

Pulmonary specialist visits in the I year before index

hospitalization

No $\quad 2,323(62.00) \quad 1,767(76.20)$

Yes $\quad 1,424(38.00) \quad 552(23.80)$

Length of hospital stay in $\quad 4.32 \pm 2.93 \quad 4.02 \pm 2.55$

days (mean $\pm \mathrm{SD}$ )

Pulmonary specialist visit during hospitalization

No $\quad 2,978(79.48) \quad 1,932(83.31)$

0.04

0.32

$<0.0001$

$<0.000$ I

Yes $769(20.52) \quad 3,87(16.69)$

Notes: Data presented as number (\%) unless otherwise stated. a Users defined as those who had a prescription filled for LABDs with or without ICSs within 90 days prior to and 30 days after hospitalization. bNonusers are those who did not have a prescription filled for LABDs with or without ICSs within 90 days prior to and 30 days after hospitalization.

Abbreviations: LABDs, long-acting bronchodilators; ICSs, inhaled corticosteroids; $\mathrm{ICU}$, intensive care unit; $\mathrm{CCU}$, coronary care unit.

We performed the following sensitivity analyses to explain the robustness of our findings. First, we limited the analysis to patients discharged with a principal diagnosis of acute exacerbation of COPD (AECOPD; primary ICD-9 code 491.21 or primary ICD-9 codes $518.81,518.82,518.84$ and 799.1 with secondary ICD-9 code 491.21). Second, we performed propensity score matching. We did 1:1 match for every "nonuser" to a "user" based on estimated propensity scores from a logistic regression model adjusted for all variables in Table 1. The matching was based on nearest Mahalanobis distance. Finally, we examined the impact of medication adherence during the 120 days studied. Adherence was defined as low, moderate or high based on $<50 \%$, $50 \%-79 \%$ or $\geq 80 \%$ of days covered, respectively. 
All analyses were performed using SAS version 9.4 (SAS Inc., Cary, NC, USA). All reported $P$-values were twosided, and $P<0.05$ was considered statistically significant.

\section{Results}

In 2011, 6,066 patients with COPD who had a hospitalization were included in the study. Of these, 3,747 (61.8\%) filled a prescription for LABDs \pm ICSs from 90 days prior to the index hospitalization to 30 days after discharge.

The baseline characteristic of "users" and "nonusers" of LABDs \pm ICSs is presented in Table 1. Patients who received a prescription for $\mathrm{LABDs} \pm$ ICSs were younger, more likely to have lower socioeconomic status and had more emergency admissions. They were more likely to be admitted to for-profit hospitals. The "user" and "nonuser" groups had a similar distribution of comorbidities. However, LABDs \pm ICSs "users" were more likely to be on oxygen therapy in the year prior to hospitalization and were more likely to be under the care of a pulmonary physician, suggesting more severe disease. Length of stay for the index hospitalization was longer for the "user" group than for the "nonuser" group (4.32 days vs 4.02 days, $P$-value 0.0001 ). A larger proportion of "users" were seen by a pulmonary physician during the index hospitalization ( $20.5 \%$ vs $16.7 \%, P$-value 0.0002$)$ compared to "nonusers".

Health-care utilization in terms of ER visits and readmissions is presented in Table 2. The "user" and "nonuser" groups had similar rates of all-cause ER visits and readmissions within 30 days of discharge date $(22.4 \%$ vs $20.7 \%$, $P$-value $0.11 ; 18.0 \%$ vs $17.8 \%, P$-value 0.85 , respectively). However, compared to "nonusers", LABDs \pm ICSs "users" had higher rates of COPD-related ER visits (5.3\% vs 3.4\%, $P$-value 0.0006$)$ and COPD-related readmissions $(7.8 \%$ vs $5.0 \%, P$-value $<0.0001)$. After adjusting for all variables in Table 1, "users" had 1.47 greater odds of a COPD-related
ER visit (95\% CI, 1.11-1.93) and 1.48 greater odds of a readmission (95\% CI, 1.18-1.86) than "nonusers".

Restricting patients to those with AECOPD (ICD-9 code 491.21, $n=3,925$ ) did not change our results. For example, the risk of a COPD-related ER visit was $6.0 \%$ vs $3.9 \%$ $(P$-value 0.004$)$ and of a COPD-related readmission was $8.5 \%$ vs $5.4 \%$ ( $P$-value 0.0003$)$ in LABDs \pm ICSs "users" vs "nonusers" (Table S1).

Based on the propensity score, we were able to match 95.5\% of "nonusers" with LABDs \pm ICSs "users" ( $n=2,214$ in each group). Figure 3 shows the distribution of propensity score of the two groups before and after matching. As shown, the propensity score overlaid well after matching, and no significant differences in patient characteristics were found between the matched groups. Outcomes were similar, with "users" having an adjusted 1.45 increased risk of a COPD-related ER visit (95\% CI, 1.07-1.96) and 1.34 adjusted greater odds of readmission (95\% CI, 1.04-1.73) compared to "nonusers" (Figure 4 and Table S2). Medication adherence rates based on PDC during the 120-day period were not associated with risk of all-cause or COPD-related readmission. Among "users", 966 patients had 30-day readmission (all-cause and COPD-related) and average cost was US\$11,499.56 (median $\$ 7,835$, quartile (Q) $1=\$ 5,826$, $\mathrm{Q} 3=\$ 12,307)$. Total 30-day readmission among "nonusers" was 527 with an average cost of US\$10,829.84 (median $\$ 7,139, \mathrm{Q} 1=\$ 5,428.5, \mathrm{Q} 3=\$ 11,378)$. There was no difference in cost between the "user" and "nonuser" groups.

\section{Discussion}

Our study found that the use of LABDs \pm ICSs as maintenance therapy in COPD patients during 90 days prior to and 30 days after hospitalization did not reduce the rate of 30-day readmission. The rates of all-cause ER visits and readmissions were similar between the "user" and "nonuser" groups.

Table 2 Health-care utilization within 30 days of discharge by LABDs \pm ICSs with or without LABDs \pm ICSs users and nonusers groups

\begin{tabular}{|c|c|c|c|}
\hline \multirow[t]{2}{*}{ Outcomes } & \multicolumn{2}{|l|}{ LABDs \pm ICSs } & \multirow{2}{*}{$\begin{array}{l}\text { Adjusted OR }(95 \% \mathrm{Cl})^{c} \\
\text { ref }=\text { nonuser }\end{array}$} \\
\hline & $\begin{array}{l}\text { Nonusers }^{\mathrm{a}} \text {, } \\
3,747, \mathrm{n}(\%)\end{array}$ & $\begin{array}{l}\text { Users }^{\mathrm{b}} \text {, } \\
2,319, \text { n (\%) }\end{array}$ & \\
\hline All-cause ER visit & $480(20.7)$ & $840(22.4)$ & $1.07(0.94-1.23)$ \\
\hline COPD-related ER visit & $78(3.4)$ & $197(5.3)^{d}$ & $1.47(1.11-1.93)^{\mathrm{d}}$ \\
\hline All-cause readmission & $412(17.8)$ & $673(18.0)$ & $0.96(0.83-1.11)$ \\
\hline COPD-related readmission & $115(5.0)$ & $293(7.8)^{d}$ & $1.48(1.18-1.86)^{\mathrm{d}}$ \\
\hline
\end{tabular}

Notes: ${ }^{2}$ Nonusers are those who did not have a prescription filled for LABDs \pm ICSs with or without LABDs \pm ICSs from 90 days prior to and 30 days after hospitalization. bUsers defined as those who had a prescription filled for LABDs with or without ICSs from 90 days prior to and 30 days after hospitalization. 'Logistic regression model was used to estimate odds ratio, adjusted by age, gender, race, region, Medicaid eligibility, comorbidity score, number of hospital beds, medical school affiliation, type of hospital, type of admission, hospitalization in the I year before index hospitalization, ICU/CCU during hospitalization, MV during hospitalization, oxygen therapy and pulmonary specialist visit in the I year before index hospitalization, LOS and pulmonary specialist visit during hospitalization. ${ }^{d P}$-value $<0.05$.

Abbreviations: LABDs, long-acting bronchodilators; ICSs, inhaled corticosteroids; ICU, intensive care unit; CCU, coronary care unit; ER, emergency room; LOS, length of stay; MV, mechanical ventilation. 


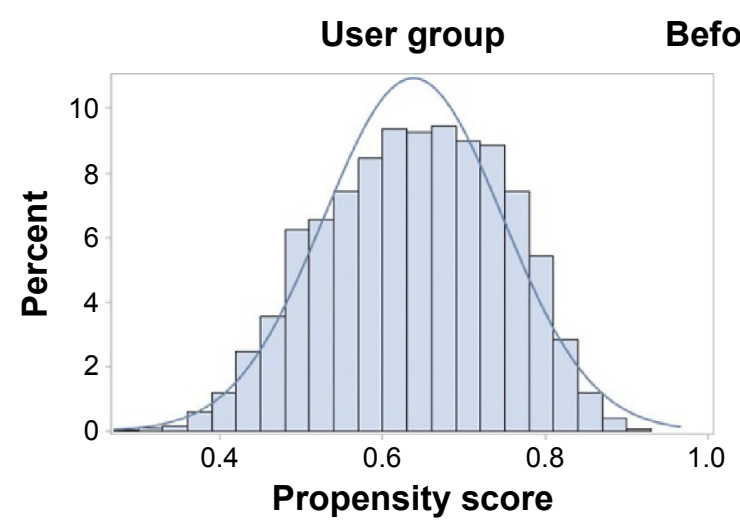

Before matching Nonuser group

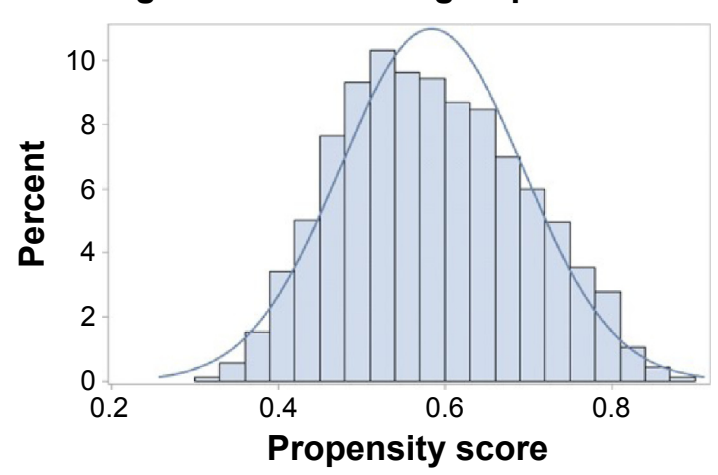

After matching
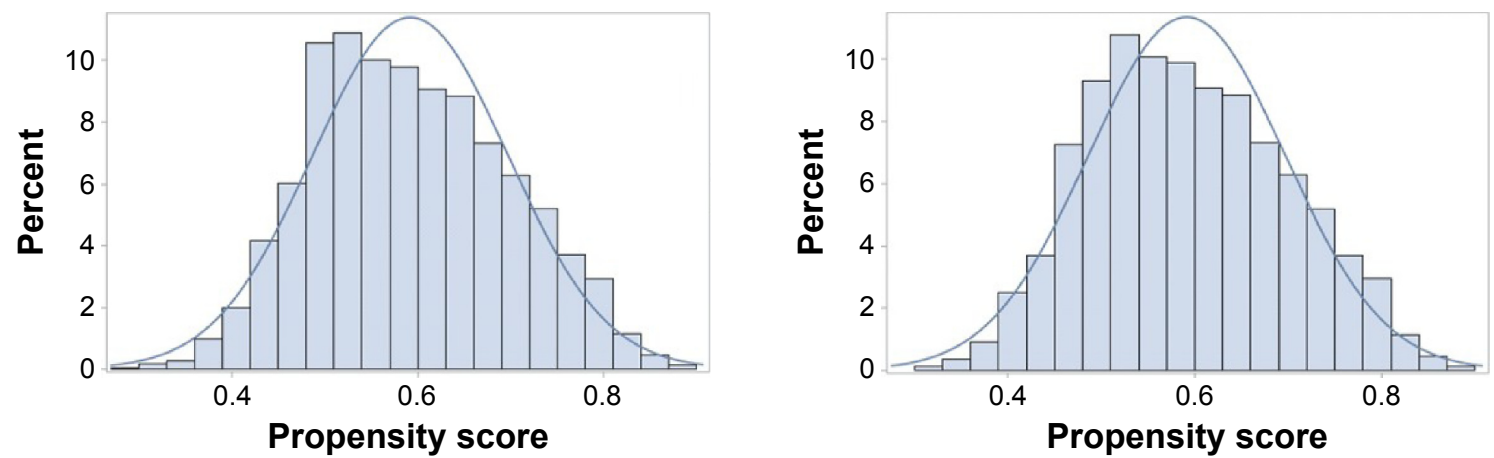

Figure 3 Propensity score distribution plot comparing LABDs \pm ICSs users vs nonusers before and after matching.

Notes: Propensity score matching adjusting for age, gender, race, region, Medicaid eligibility, comorbidity score, number of hospital beds, medical school affiliation, type of hospital, type of admission, hospitalization I year before index hospitalization, ICU/CCU during index hospitalization, MV during index hospitalization, oxygen therapy I year before index hospitalization, pulmonary specialist visit I year before index hospitalization, length of index hospitalization stay and pulmonary specialist visit during index hospitalization.

Abbreviations: LABDs, long-acting bronchodilators; ICSs, inhaled corticosteroids; ICU, intensive care unit; CCU, coronary care unit; MV, mechanical ventilation.

Higher rates of COPD-related ER visits and 30-day readmissions in patients on maintenance drugs are likely related to illness severity rather than causal. LABAs with or without ICSs and LAMA use in stable patients with COPD have been shown to prevent exacerbations, reduce hospitalizations and improve both lung function and quality of life. ${ }^{3,24-26}$ Our study showed that the use of maintenance medication did not reduce early readmission.

More than half of readmissions in patients hospitalized for COPD are non-COPD related and not all COPDrelated readmissions are related to AECOPD. ${ }^{17}$ Numerous factors related to patient disease severity, comorbidity and health-care delivery play a role in 30-day readmission. ${ }^{29-31}$ LABDs \pm ICSs has a role in preventing exacerbations in stable patients with $\mathrm{COPD}^{3,24-26,32,33}$ but not per se in reducing 30-day readmissions.

The findings of our study are similar to prior reports. Lindenauer et $\mathrm{al}^{34}$ showed that the use of LABDs in patients hospitalized for AECOPD was not associated with better outcomes. Instead, 30-day LABDs-related readmission rates were higher in patients treated with LABDs when compared with those who received short-acting bronchodilators for AECOPD (3.1\% vs 2.6\%, $P$-value $<0.001) .{ }^{34}$ Baker et al ${ }^{35}$ showed that the use of LABDs after hospitalization for COPD was associated with higher rates of ER visits (17.8\% vs $14.1 \%, P$-value $<0.0001)$ and hospitalization $(16.0 \%$ vs $12.6 \%, P$-value $<0.001$ ) within 90 days compared to nonusers of LABDs \pm ICSs.

These findings taken together could merely reflect that sicker individuals are on maintenance drugs and sicker people get rehospitalized. The other explanation could be related to the differential mechanism of these drugs during exacerbation and recovery phase, which makes patients prone to poor symptoms control after discharge, requiring readmission. Functional antagonism and receptor downregulation can occur during exacerbations due to strong cholinergic tone, and prolonged use of long-acting agents may necessitate an increased need for short-acting beta agonist. ${ }^{36-38}$ Excessive 


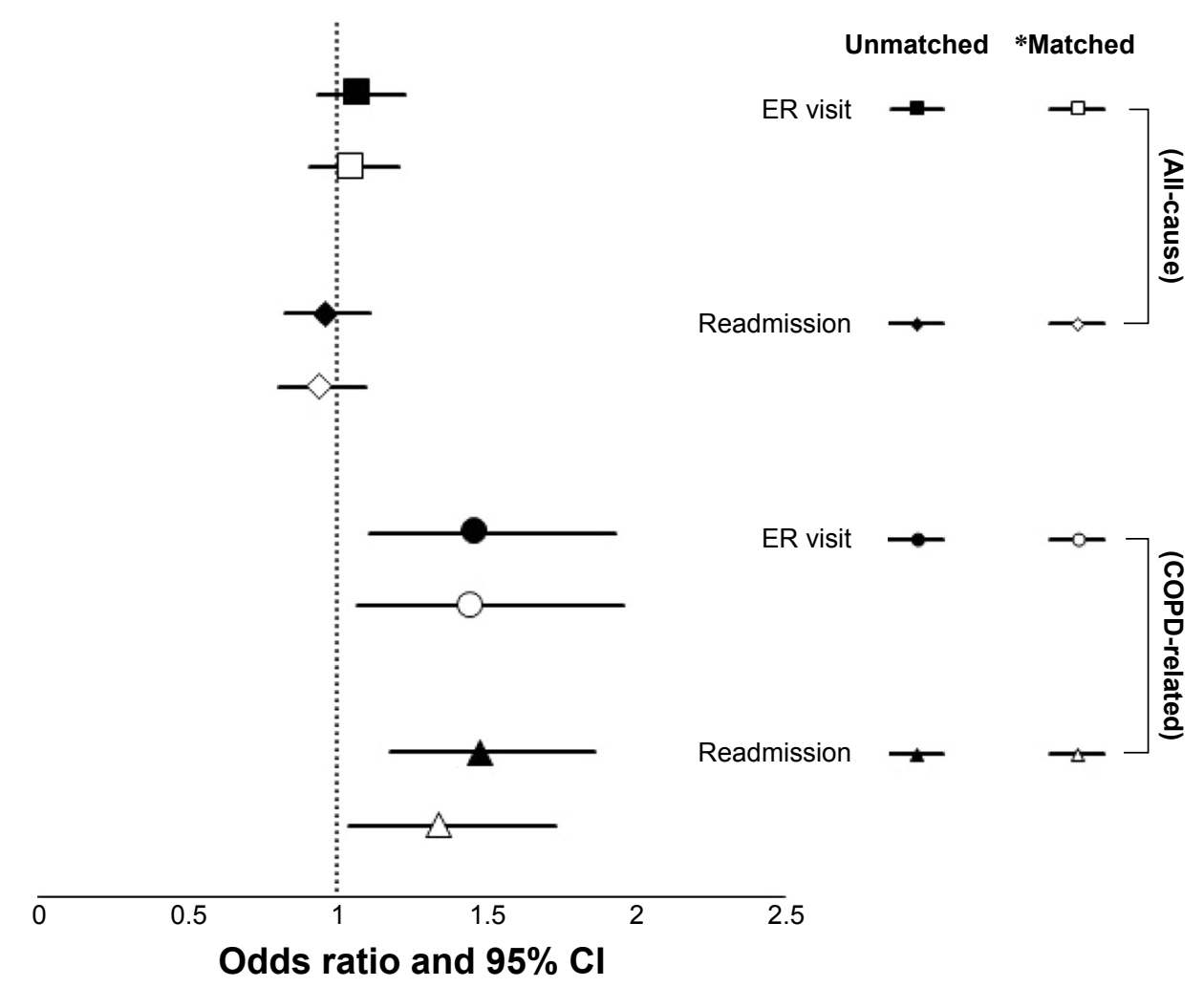

Figure 4 Odds of ER visit and readmission within 30 days after index hospitalization related to COPD in patients using LABDs \pm ICSs 90 days prior to hospitalization and/ or 30 days after discharge.

Notes: *Matched: propensity score matching adjusted for age, gender, race, region, Medicaid eligibility, comorbidity score, number of hospital beds, medical school affiliation, type of hospital, type of admission, hospitalization I year before index hospitalization, ICU/CCU during index hospitalization, MV during index hospitalization, oxygen therapy I year before index hospitalization, pulmonary specialist visit I year before index hospitalization, length of index hospitalization stay and pulmonary specialist visit during index hospitalization.

Abbreviations: LABDs, long-acting bronchodilators; ICSs, inhaled corticosteroids; ICU, intensive care unit; CCU, coronary care unit; ER, emergency room; MV, mechanical ventilation

use of beta agonist and antimuscarinic agents can predispose patients to adverse cardiovascular side effects such as tachycardia, arrhythmias and congestive heart failure, resulting in an increase in all-cause ER visits and readmissions. ${ }^{29}$

Our findings should be considered in the context of our study's limitations. First, our study is limited to fee-for-service Medicare beneficiaries who had Medicare Parts A, B and D. Second, we used ICD-9 codes to establish a diagnosis of COPD, and these codes may not reflect disease severity. However, we were able to control for other surrogates of disease severity such as prior hospitalization, oxygen use, ICU/CCU and mechanical ventilation use during index hospitalization, whether the patient was under the care of a pulmonary physician in the year prior to the hospitalization and whether the patient was seen by a pulmonary provider during the index hospitalization. Third, we defined LABDs/LABDs \pm ICSs users as those who had a prescription filled within the 90 days prior to the index hospitalization and 30 days after discharge; however, these data may not capture actual use. Even though high medication adherence measured as PDC was not associated with reduced risk of all-cause or COPD-related readmission, the reasons for readmissions in this chronically ill population are multifactorial and may not be amenable to the use of maintenance medication. Fourth, we did not examine the role of early follow-up, pulmonary rehabilitation or disease management in our study. To date, none of these approaches has been shown to reduce readmission, in well-designed studies.

\section{Conclusion}

We found that the use of maintenance drugs LABDs \pm ICSs 90 days prior to and 30 days after hospitalization for COPD did not reduce 30 -day readmission.

\section{Acknowledgments}

The authors thank Sarah Toombs-Smith, PhD, ELS for helping with the preparation of the manuscript. This work was supported by the: 1) Agency for Healthcare Research and Quality (R01-HS020642) and by the Patient Centered Outcomes Research Institute (1R24HS022134-03), 2) Clinical and Translational Science Award (1UL1TR001439-01) from the National Center for Advancing Translational Sciences and, 3) Claude D Pepper OAIC grant number P30 AG024832-11. 
Funders had no role in the preparation, approval or submission of the results.

\section{Disclosure}

Dr Sharma serves on the advisory board of Theravance Biopharma, Mylan and Sunovion pharmaceutical companies. The authors report no other conflicts of interest in this work.

\section{References}

1. Fletcher C, Peto R. The natural history of chronic airflow obstruction. Br Med J. 1977;1(6077):1645-1648.

2. Rennard SI, Vestbo J. Natural histories of chronic obstructive pulmonary disease. Proc Am Thorac Soc. 2008;5(9):878-883.

3. Global Initiative for Chronic Obstructive Lung Disease. Global Strategy for the Diagnosis, Management and Prevention of COPD-2016, Available from: http://goldcopd.org/global-strategy-diagnosis-managementprevention-copd-2016/. September 1, 2016.

4. Donaldson G, Seemungal T, Bhowmik A, Wedzicha J. Relationship between exacerbation frequency and lung function decline in chronic obstructive pulmonary disease. Thorax. 2002;57(10):847-852.

5. Miravitlles M, Ferrer M, Pont A, et al. Effect of exacerbations on quality of life in patients with chronic obstructive pulmonary disease: a 2 year follow up study. Thorax. 2004;59(5):387-395.

6. Makris D, Moschandreas J, Damianaki A, et al. Exacerbations and lung function decline in COPD: new insights in current and ex-smokers. Respir Med. 2007;101(6):1305-1312.

7. Soler-Cataluña JJ, Rodriguez-Roisin R. Frequent chronic obstructive pulmonary disease exacerbators: how much real, how much fictitious? COPD. 2010;7(4):276-284.

8. Seemungal TA, Donaldson GC, Paul EA, Bestall JC, Jeffries DJ, Wedzicha JA. Effect of exacerbation on quality of life in patients with chronic obstructive pulmonary disease. Am J Respir Crit Care Med. 1998;157(5 pt 1):1418-1422.

9. Soler-Cataluña JJ, Martínez-García MA, Román Sánchez P, Salcedo E, Navarro M, Ochando R. Severe acute exacerbations and mortality in patients with chronic obstructive pulmonary disease. Thorax. 2005;60(11):925-931.

10. Hoogendoorn M, Hoogenveen RT, Rutten-van Mölken MP, Vestbo J, Feenstra TL. Case fatality of COPD exacerbations: a meta-analysis and statistical modelling approach. Eur Respir J. 2011;37(3): $508-515$.

11. Niewoehner DE, Lokhnygina $Y$, Rice K, et al. Risk indexes for exacerbations and hospitalizations due to COPD. Chest. 2007;131(1):20-28.

12. Baker CL, Zou KH, Su J. Risk assessment of readmissions following an initial COPD-related hospitalization. Int J Chron Obstruct Pulmon Dis. 2013;8:551-559.

13. Elixhauser A, Au DH, Podulka J. Readmissions for Chronic Obstructive Pulmonary Disease, 2008: Statistical Brief \#121 [Internet]. In: Healthcare Cost and Utilization Project (HCUP) Statistical Briefs. Rockville (MD): Available from: http://www.ncbi.nlm.nih.gov/books/ NBK65392/. Accessed September 1, 2016.

14. Ford ES, Murphy LB, Khavjou O, Giles WH, Holt JB, Croft JB. Total and state-specific medical and absenteeism costs of COPD among adults aged $\geq 18$ years in the United States for 2010 and projections through 2020. Chest. 2015;147(1):31-45.

15. CMS. Medicare Hospital Quality Chartbook - Performance Report on Outcome Measures, September 2013 - Medicare-Hospital-QualityChartbook-2013.pdf. Available from: https://www.cms.gov/Medicare/ Quality-Initiatives-Patient-Assessment-Instruments/HospitalQualityInits/ Downloads/-Medicare-Hospital-Quality-Chartbook-2013.pdf. Accessed September 1, 2016.
16. Hines AL, Barrett ML, Jiang HJ, Steiner CA. Conditions with the largest number of adult hospital readmissions by payer, 2011;2014 [cited January 6, 2016]. Available from: http://www.ncbi.nlm.nih.gov/books/ NBK206781/. September 1, 2016.

17. Jencks SF, Williams MV, Coleman EA. Rehospitalizations among patients in the Medicare fee-for-service program. N Engl J Med. 2009; 360(14):1418-1428.

18. Sharma G, Kuo Y-F, Freeman JL, Zhang DD, Goodwin JS. Outpatient follow-up visit and 30-day emergency department visit and readmission in patients hospitalized for chronic obstructive pulmonary disease. Arch Intern Med. 2010;170(18):1664-1670.

19. Hansen LO, Greenwald JL, Budnitz T, et al. Project BOOST: effectiveness of a multihospital effort to reduce rehospitalization. J Hosp Med. 2013;8(8):421-427.

20. Markley J, Andow V, Sabharwal K, Wang Z, Fennell E, Dusek R. A project to reengineer discharges reduces 30 -day readmission rates. Am J Nurs. 2013;113(7):55-64.

21. Krishnan JA, Gussin HA, Prieto-Centurion V, Sullivan JL, Zaidi F, Thomashow BM. Integrating COPD into patient-centered hospital readmissions reduction programs. Chronic Obstr Pulm Dis. 2015;2(1): 70-80.

22. Prieto-Centurion V, Markos MA, Ramey NI, et al. Interventions to reduce rehospitalizations after chronic obstructive pulmonary disease exacerbations. A systematic review. Ann Am Thorac Soc. 2014;11(3): 417-424.

23. Jennings JH, Thavarajah K, Mendez MP, Eichenhorn M, Kvale P, Yessayan L. Predischarge bundle for patients with acute exacerbations of COPD to reduce readmissions and ED visits: a randomized controlled trial. Chest. 2015;147(5):1227-1234.

24. Tashkin DP, Fabbri LM. Long-acting beta-agonists in the management of chronic obstructive pulmonary disease: current and future agents. Respir Res. 2010;11:149.

25. Kew KM, Mavergames C, Walters JAE. Long-acting beta2-agonists for chronic obstructive pulmonary disease. Cochrane Database Syst Rev. 2013;10:CD010177.

26. Cheyne L, Irvin-Sellers MJ, White J. Tiotropium versus ipratropium bromide for chronic obstructive pulmonary disease. Cochrane Database Syst Rev. 2015;9:CD009552.

27. Calverley PMA, Rabe KF, Goehring U-M, et al. Roflumilast in symptomatic chronic obstructive pulmonary disease: two randomised clinical trials. Lancet. 2009;374(9691):685-694.

28. Fu AZ, Sun SX, Huang X, Amin AN. Lower 30-day readmission rates with roflumilast treatment among patients hospitalized for chronic obstructive pulmonary disease. Int J Chron Obstruct Pulmon Dis. 2015; 10:909-915.

29. Sharif R, Parekh TM, Pierson KS, Kuo Y-F, Sharma G. Predictors of early readmission among patients 40 to 64 years of age hospitalized for chronic obstructive pulmonary disease. Ann Am Thorac Soc. 2014; 11(5):685-694.

30. Singh G, Zhang W, Kuo Y-F, Sharma G. Association of psychological disorders with 30-day readmission rates in patients with COPD. Chest. 2016;149(4):905-915.

31. Amalakuhan B, Kiljanek L, Parvathaneni A, Hester M, Cheriyath P, Fischman D. A prediction model for COPD readmissions: catching up, catching our breath, and improving a national problem. J Community Hosp Intern Med Perspect. 2012;2(1).10.3402/jchimp.v2i1.9915.

32. Criner GJ, Bourbeau J, Diekemper RL, et al. Executive summary: prevention of acute exacerbation of COPD: American College of Chest Physicians and Canadian Thoracic Society Guideline. Chest. 2015; 147(4):883-893.

33. Welte T, Miravitlles M, Hernandez P, et al. Efficacy and tolerability of budesonide/formoterol added to tiotropium in patients with chronic obstructive pulmonary disease. Am J Respir Crit Care Med. 2009;180(8): 741-750.

34. Lindenauer PK, Shieh M-S, Pekow PS, Stefan MS. Use and outcomes associated with long-acting bronchodilators among patients hospitalized for chronic obstructive pulmonary disease. Ann Am Thorac Soc. 2014; 11(8):1186-1194. 
35. Baker CL, Zou KH, Su J. Long-acting bronchodilator use after hospitalization for COPD: an observational study of health insurance claims data. Int J Chron Obstruct Pulmon Dis. 2014;9:431-439.

36. Turner A, Ejiofor S, Turner A. Pharmacotherapies for COPD. Clin Med Insights Circ Respir Pulm Med. 2013;7:17-34.

37. Cockcroft DW, Swystun VA. Functional antagonism: tolerance produced by inhaled beta 2 agonists. Thorax. 1996;51(10):1051-1056.
38. van der Woude HJ, Winter TH, Aalbers R. Decreased bronchodilating effect of salbutamol in relieving methacholine induced moderate to severe bronchoconstriction during high dose treatment with long acting beta2 agonists. Thorax. 2001;56(7):529-535. 


\section{Supplementary materials}

Table SI Health-care utilization within 30 days of discharge by LABDs with or without ICSs users and nonusers group for AECOPD, $\mathrm{N}=3,925$

\begin{tabular}{|c|c|c|c|}
\hline \multirow[t]{2}{*}{ Outcomes } & \multicolumn{2}{|l|}{ LABDs \pm ICSs } & \multirow{2}{*}{$\begin{array}{l}\text { Adjusted OR }(95 \% \mathrm{Cl})^{\mathrm{d}} \text {, } \\
\text { ref }=\text { nonuser }\end{array}$} \\
\hline & $\begin{array}{l}\text { Nonusers } \\
\mathrm{n}=2,504, \mathrm{n} \text { (\%) }\end{array}$ & $\begin{array}{l}\text { Users', } \\
n=I, 42 I, n(\%)\end{array}$ & \\
\hline All-cause ER visit & $302(21.25)$ & $593(23.68)$ & I.II (0.94-I.3I) \\
\hline COPD-related ER visit & $55(3.87)$ & $|5|(6.03)^{e}$ & $1.42(1.02-1.98)^{\mathrm{e}}$ \\
\hline All-cause readmission & $269(18.93)$ & $493(19.69)$ & $1.00(0.84-1.19)$ \\
\hline COPD-related readmission & $76(5.35)$ & $213(8.5 \mathrm{I})^{\mathrm{e}}$ & $1.48(1.14-1.99)^{\mathrm{e}}$ \\
\hline
\end{tabular}

Notes: aAECOPD is defined as hospitalization with a primary ICD-9 code (49I.2I) or primary ICD-9 codes for respiratory failure $(518.81,518.82,518.84$ and 799.1$)$ with secondary ICD-9 code (49I.2I). ${ }^{\text {NN}}$ Nonusers are those who did not have a prescription filled for LABDs with or without ICSs from 90 days prior to and 30 days after hospitalization. 'Users defined as those who had a prescription filled for LABDs with or without ICSs from 90 days prior to and 30 days after hospitalization. ${ }^{\circledR}$ Logistic regression model was used to estimate odds ratio, adjusted by age, gender, race, region, Medicaid eligibility, comorbidity score, number of hospital beds, medical school affiliation, type of hospital, type of admission, hospitalization in the I year before index hospitalization, ICU/CCU during hospitalization, MV during hospitalization, oxygen therapy and pulmonary specialist visit in the I year before index hospitalization, LOS and pulmonary specialist visit during hospitalization. ${ }^{e}$-value $<0.05$.

Abbreviations: LABSs, long-acting bronchodilators; ICSs, inhaled corticosteroids; AECOPD, acute exacerbation of COPD; ICD-9, International Classification of Diseases, Ninth Revision; ER, emergency room; ICU, intensive care unit; CCU, coronary care unit; LOS, length of stay; MV, mechanical ventilation.

Table S2 Health-care utilization within 30 days of discharge by LABDs with or without ICSs users and nonusers group after propensity matching, $\mathrm{N}=4,428$

\begin{tabular}{|c|c|c|c|}
\hline \multirow[t]{2}{*}{ Outcomes } & \multicolumn{2}{|l|}{ LABDs \pm ICSs } & \multirow{2}{*}{$\begin{array}{l}\text { Adjusted OR }(95 \% \mathrm{Cl})^{c} \text {, } \\
\text { ref }=\text { nonuser }\end{array}$} \\
\hline & $\begin{array}{l}\text { Nonusers } \\
n=2,2 \mid 4, n(\%)\end{array}$ & $\begin{array}{l}\text { Users }^{b} \\
n=2,214, n \text { (\%) }\end{array}$ & \\
\hline All cause ER visit & $452(20.42)$ & $469(21.18)$ & $1.05(0.9 I-1.2 I)$ \\
\hline COPD-related ER visit & $75(3.39)$ & $107(4.83)^{d}$ & $1.45(1.07-1.96)^{\mathrm{d}}$ \\
\hline All cause readmission & $393(17.75)$ & 375 (16.94) & $0.94(0.8 I-1.10)$ \\
\hline COPD-related readmission & $110(4.97)$ & $145(6.55)^{d}$ & $1.34(1.04-1.73)^{d}$ \\
\hline
\end{tabular}

Notes: ${ }^{a}$ Nonusers are those who did not have a prescription filled for LABDs with or without ICSs from 90 days prior to and 30 days after hospitalization. ${ }^{\text {b }}$ sers defined as those who had a prescription filled for LABDs with or without ICSs from 90 days prior to and 30 days after hospitalization. 'Logistic regression model was used to estimate odds ratio, adjusted by age, gender, race, region, Medicaid eligibility, comorbidity score, number of hospital beds, medical school affiliation, type of hospital, type of admission, hospitalization in the I year before index hospitalization, ICU/CCU during hospitalization, MV during hospitalization, oxygen therapy and pulmonary specialist visit in the I year before index hospitalization, LOS, and pulmonary specialist visit during hospitalization. ${ }^{\mathrm{d} P}$-value $<0.05$.

Abbreviations: LABDs, long-acting bronchodilators; ICSs, inhaled corticosteroids; ICU, intensive care unit; CCU, coronary care unit; ER, emergency room; LOS, length of stay; MV, mechanical ventilation.

\section{Publish your work in this journal}

The International Journal of COPD is an international, peer-reviewed journal of therapeutics and pharmacology focusing on concise rapid reporting of clinical studies and reviews in COPD. Special focus is given to the pathophysiological processes underlying the disease, intervention programs, patient focused education, and self management protocols.

\section{Dovepress}

This journal is indexed on PubMed Central, MedLine and CAS. The manuscript management system is completely online and includes a very quick and fair peer-review system, which is all easy to use. Visit $\mathrm{http}: / /$ www.dovepress.com/testimonials.php to read real quotes from published authors. 